\title{
DO BONE INGROWTH PROCESSES PRODUCE A GLOBALLY OPTIMIZED STRUCTURE?
}

\begin{abstract}
S. J. Hollister*, N. Kikuchi† and S. A. Goldstein*
*Orthopaedic Research Laboratories, Section of Orthopaedic Surgery. The University of Michigan, Ann Arbor, MI 48109, U.S.A.; and † Computational Mechanics Laboratory, The Department of Mechanical Engineering and Applied Mechanics, The University of Michigan, Ann Arbor, MI 48109. U.S.A.

Abstract-A topology optimization program was applied to test the hypothesis that bone adaptation to porous coated implants produces a structure which minimizes the global strain energy density. The program was used to predict the optimal material layout around a porous coated tibial component with multiple cones [Goldstein et al., Trans. 37th ORS, p. 92(1991)]. The sensitivity of the predicted adaptation to analysis assumptions was assessed and the predicted bone ingrowth and apposition were compared with the experimental findings of Goldstein et al. The results showed that apposition occurred consistently at the cone tips regardless of analysis assumptions. The specific topology of apposition at the cone tips was most sensitive to the assumed loading conditions. A comparison with the experimental results for 11 subdivisions showed that the general predicted location of material agreed with the experimental results $\left(R^{2} \geqslant 0.59\right)$. However, the program predicted a consolidated bone greater than $1000 \mu \mathrm{m}$ in thickness at the cone tips, which differed from the porous bone structure found experimentally. This discrepancy was reflected in a refined comparison over 31 subdivisions which did not produce a significant correlation $\left(R^{2} \leqslant 0.3\right)$. The program also predicted little ingrowth $(<6-7 \%)$, indicating that ingrowth past the first bead layer contributed little to the overall bone-implant interface layer stiffness. Based on these results, we conclude, within limitations of a two-dimensional analysis, that bone adaptation to porous coated implants does not produce a structure solely optimized to minimize the global strain energy density. We hypothesize that the final bone structure reflects the need to meet both mechanical and nutritional demands.
\end{abstract}

\section{INTRODUCTION}

Bone ingrowth into a porous coated surface has received widespread attention as an alternative to bone cement for fixation of total joint replacement prostheses. Initial clinical results from porous coated prostheses have been encouraging, with good to excellent results reported after a two- to four-year followup (Galante, 1988; Hungerford and Kenna, 1983; Hungerford et al., 1988). However, many animal studies (Bobyn et al., 1982; Hedley et al., 1982; Turner et al., 1989) and studies of retrieved human implants (Collier et al., 1988, 1992; Cook 'et al., 1988, 1989; Engh et al., 1988; Galante and Jacobs, 1992; Hainau et al., 1989; Sumner et al., 1989) have shown that bone volume fraction within the porous coating is low, in general less than $35 \%$. In fact, most studies of retrieved human implants report the volume fraction of ingrowth to be less than $20 \%$ (Table 1). In these studies, ingrowth for tibial and acetabular components was found primarily on or near the fixation pegs, which are points of high load transfer between implant and bone. These clinical and experimental observations suggest that cellular

Accepted in final form 4 November 1992.

Presented in part at the combined meeting of the U.S.A.. Japan, and Canada ORS.

Address Correspondence: Scott J. Hollister, Ph.D., Orthopaedic Research Laboratories, $400 \mathrm{~N}$. Ingalls Building, The University of Michigan, Ann Arbor, MI 48109, U.S.A. processes controlling bone ingrowth are significantly influenced by the mechanical environment at the bone-implant interface.

A histological study of the bone-porous-coating interface indicates that the process of bone ingrowth is similar to a fracture healing response (Galante et al., 1986; Jasty and Harris, 1988; Sevitt, 1981; Spector, 1988). Injury to interface trabecular bone during implantation causes a hematoma to develop, which is replaced by a primitive mesenchymal tissue. The mesenchymal tissue may then differentiate into woven bone or fibrous tissue (Galante et al., 1986). Areas of woven bone tissue are either remodeled to produce secondary lamellar bone or resorbed to produce fibrous tissue. The initial woven bone formation results from an accelerated injury response [denoted as the regional acceleratory phenomena by Frost (1986b)] which may be initially nonspecific in that the injury response is constant along the implant interface. The later remodeling of this woven bone tissue, however, is believed to be significantly influenced by the mechanical environment at the interface (Galante et al., 1986).

Based on histological evidence that a fracture healing response occurs at the implant interface, and on recent in vivo studies which show that bone adaptation occurs locally near the porous-coating-bone interface (Cheal et al., 1987; Goldstein et al., 1991a), we believe that the response of bone to porous coated implants may be divided into two regional responses. 
Table 1. Summary of observed amount and location of bone ingrowth for tibial acetabular, and distal femoral porous coated components with fixation pegs. All studies report ingrowth fixation on or near pegs. Some studies (Cook et al., 1988; Engh, 1988; Hainau et al., 1989) report no bone ingrowth at the component plates. Other studies (Bobyn et al., 1982; Cook et al., 1989; Galante and Jacobs, 1992; Sumner et al., 1989; Turner et al., 1989) report varied amounts of ingrowth at the component base. The finding that ingrowth occurs most often at the fixation pegs concurs with results indicating that protruding pegs are the more optimal material location for creating a stiff implant-bone interface in components containing such pegs

\begin{tabular}{lccll}
\hline Authors & Species & $\begin{array}{l}\text { Number of } \\
\text { components }\end{array}$ & $\begin{array}{l}\text { Anatomic location } \\
\text { of component }\end{array}$ & Quantification \\
\hline Engh et al (1988) Human & 2 & Proximal tibia & $\begin{array}{l}\text { Histological analysis. } \\
\text { Did not report } \\
\text { measurements. }\end{array}$
\end{tabular}

\begin{tabular}{|c|c|c|c|c|}
\hline $\begin{array}{l}\text { Cook et al. } \\
\text { (1988) }\end{array}$ & Human & 24 & Acetabulum & $\begin{array}{l}\text { Histological analysis. } \\
\text { Volume fraction of bone } \\
\text { ingrowth measured.* } \\
\text { No component had } \\
\text { more than } 10 \% \text {. }\end{array}$ \\
\hline $\begin{array}{l}\text { Collier et al. } \\
(1988)\end{array}$ & Human & 58 & Acetabulum & $\begin{array}{l}\text { Histologic analysis. } \\
\text { No quantification of } \\
\text { extent of bone ingrowth. }\end{array}$ \\
\hline $\begin{array}{l}\text { Cook et al. } \\
\text { (1989) }\end{array}$ & Human & 60 & $\begin{array}{l}\text { Proximal tibia } \\
\text { (34 components) } \\
\text { Distal fernur } \\
\text { (26 components) }\end{array}$ & $\begin{array}{l}\text { Histological analysis of } \\
\text { the volume fraction of } \\
\text { ingrowth.* All compon- } \\
\text { ents had less than } 10 \% \text {. } \\
92 \% \text { of distal femur and } \\
97 \% \text { of tibial compon- } \\
\text { ents had less than } 5 \%\end{array}$ \\
\hline
\end{tabular}

Sumner et al. Human $\quad 10 \quad$ Proximal tibia

Measured percentage of component covered with at least partial bone ingrowth. Found mean extent of surface with some ingrowth to be $25.1 \%$

Observation on bone ingrowth and apposition location (1989)

$\begin{array}{llll}\begin{array}{l}\text { Hainau et al. } \\ \text { (1989) }\end{array} & \text { Human } & 1 & \begin{array}{l}\text { Proximal tibi } \\ \text { (Unicompart- } \\ \text { mental) }\end{array}\end{array}$

Galante and Human $14 \quad$ Acetabulum
Jacobs (1992)

Bobyn et al. Canine $\quad 6 \quad$ Distal femur (1982)

Turner et al. Canine (1989)

6 Proximal tibia

Histologic analysis. No measurements reported.
Measured percentage of component with at least partial bone ingrowth. + Found extent of tray in- growth ranged from 12 to $81 \%$.

\section{Histology showed bone growth into fixation peg but none under plateau (p. 727). Also reported high ra- dioluciences under plateau associated with fibrous tissue. \\ Bone ingrowth only found in and around fixation pegs of acetabular components (p. 97).}

Of the acetabulum components nine out of 58 showed evidence of bone ingrowth fixation. (p. 177).

Bone ingrowth was found in the vicinity of pegs in both distal femoral and tibia components ( $p$.

S35-36). Bone ingrowth also seen where tibial tray contacted cortical shell. Bone ingrowth rarely observed on posterior portion of tibial tray.

All fixation pcgs in eight of the 10 components had ingrowth. In the other two components, three of the four pegs had ingrowth.

Bone ingrowth on tray commonly seen in central portion. Rest of tray covered with fibrous tissue.

Found only fibrous collagen tissue within porous coating.

Mean volume fraction of bone ingrowth for acetabular components was $8.9 \%$. Bone ingrowth found in dome and near fixation screws.

Bone ingrowth into stem was very good (p. 308).

Bone ingrowth at distal plateau of component was observed initially, but decreased with time.

All tibial component pegs were contained in bone with no fibrous tissue (p. 896). Considerable variation in ingrowth along pad, with a mean of $34.6 \%$ and a standard deviation of $24.7 \%$ (p. 896).

\footnotetext{
*Volume fraction of ingrowth measured as the tolal amount of pore space occupied by bone per total pore space available. +Extent of porous surface covered by ingrowth is measured as the total number of surface regions containing some bone ingrowth divided by the total number of surfaces covering the implant.
} 
First, there is a modeling/remodeling response within a localized interface zone (probably from within the porous coating to a distance of 3-5 $\mathrm{mm}$ away from the porous coating; Cheal et al., 1987; Goldstein et al., 1991a) which produces an initially uniform distribution of woven bone tissue. The initial distribution may be uniform because the injury response is nonspecific. This woven bone tissue is then restructured to produce a distribution of lamellar bone and fibrous tissue that is optimal with respect to some mechanical objective. Second, the bone architecture outside the interface region is remodeled according to the normal activation-resorption-formation (Frost, 1986a; Jee, 1983) sequence in response to load transferred through the bone-implant interface.

This paper concentrates on investigating the mechanically adaptive interface response following initial injury. Specifically, it is hypothesized that a restricted amount of lamellar bone within the interface zone minimizes the strain energy density within the implant/interface bone-tissue composite. The restriction may result from the limits on trabeculae thickness for purposes of diffusion of nutrients to osteocytes. The initial interface zone structure is assumed to be a mixture of woven bone and fibrous tissue resulting from the injury response. From a biological standpoint, this hypothesis implies that cells in the interface tissue communicate their strain states to produce a tissue architecture which minimizes the deformation of the bone-implant composite. This hypothesis also implies that the final interface tissue architecture is relatively insensitive to the initial interface tissue density (i.e. whether woven bone or fibrous tissue is present). The insensitivity to the initial tissue structure is rationalized by the fact that the initial tissue structure is produced primarily by an injury response and may be similar along the entire implant.

To test the hypothesis that a limited amount of interface tissue minimizes the global strain energy density (SED), a topology optimization program (Bendsoe and Kikuchi, 1988; Suzuki and Kikuchi, 1990) was applied to predict material distribution around an experimental canine porous coated tibial component (Goldstein et al., 1991b). Since inaccuracies in modeling assumptions may obscure how well the stated hypothesis fits the experimental data, a sensitivity study was first performed to test how the predicted interface material distribution was quantified for representative modeling assumptions separately into bone ingrowth (tissue within the porous coating) and bone apposition (tissue from the outer bead layer to a depth of $300 \mu \mathrm{m}$ away from the outer bead). The predicted bone ingrowth and apposition were then compared with the pooled bone ingrowth and apposition measures from a 9-and a 12-month animal.

\section{BACKGROUND}

The topology optimization approach developed by Bendsoe and Kikuchi (1988) minimizes the global
SED within a given design area using an optimality criteria approach, with the only constraint being the total amount of material within the domain, termed the material constraint. The material within the domain is assumed to be composed of a very small porous microstructure. The material stiffness is then determined by the size and orientation of the microstructure. Bendsoe and Kikuchi calculated the anisotropic material stiffness on microstructural geometry using homogenization theory. The governing homogenization equations used to calculate of the anisotropic stiffness may be found in Bendsoe and Kikuchi (1988) or in Hollister et al. (1991a).

The derivative of the apparent anisotropic stiffness with respect to the microstructural porosity and orientation, called the sensitivity derivative, is part of the optimality criteria equations and is calculated explicitly from the homogenization analysis. The optimality criteria equations are derived by setting the first variation of the Lagrangian (shown below; see Taylor, 1986) to zero:

$$
\begin{gathered}
L(u, a, \theta)-\Pi_{\lambda}-\Lambda\left[\int_{\Omega_{\mathrm{s}}}\left(1-a^{2}\right) \mathrm{d} \Omega-\Omega_{\mathrm{s}}\right] \\
\stackrel{\text { first variation }}{\longrightarrow} \delta L=0,
\end{gathered}
$$

where $L$ denotes the Lagrangian, $u$ is the displacement vector, $a$ is the size of the microstructural void, $\theta$ is the microstructural orientation, $\Pi_{\lambda}$ is the total potential energy, $\Lambda$ is a Lagrange multiplier, $\Omega_{s}$ is the limit on the amount of material in the design area, and $\delta L$ denotes the first variation of the Lagrangian (Suzuki and Kikuchi, 1990). The topology optimization program solves the nonlinear optimality criteria equations using an iterative scheme. In this scheme, an initial material distribution is first chosen. The strain within this distribution is calculated by finite element analysis. The strain distribution is used with the sensitivity derivative in a recursion formula to update the microstructural porosity and orientation. The updated microstructure produces a new stiffness distribution from which a new strain distribution is calculated. This process continues until the change in SED at a given iteration is less than a user-defined tolerance. For this study, the tolerance was chosen to be small, less than 0.0001 , to guard against premature convergence. The final distribution of microstructural porosity determines the final topology of the material in that no material exists at high porosity while solid material exists at low porosity. The topology of the final structure is defined by a map of material porosity plotted on the finite element mesh of the original domain. The interested reader should consult Bendsoe and Kikuchi (1988) and Suzuki and Kikuchi (1990) for further mathematical details.

The topology optimization process is analogous to constructing individual trabeculae from small packets of material at a microstructural level. Since the objective is to minimize the global SED, the porosity of each 
packet of material is determined by its contribution to the global stiffness, of which the stress state within the material is a part. If these small packets of material are produced by the basic multicellular units (BMUs; Frost, 1986a), these BMUs would have to know the stress states of their neighbors as well as their own to determine if they should resorb or form bone. This paper applies the topology optimization program to investigate the possibility that bone cells act in concert to produce a globally optimized structure within the porous coating interface region.

\section{METHODS}

\section{Sensitivity study of modeling parameters}

A plane stress two-dimensional finite element model (Fig. 1) based on a histological section of an experimental canine tibial component with multiple conic projections (Goldstein et al., 1991 b) was analyzed. The model contained five structures with varying material properties, including the implant substrate, metal beads of the porous coating, the initial interface region tissue which is the design area, cortical shell, and struts which represented the trabecular bone outside the interface region. The element size was fixed so that the average size of one trabeculae ( $200 \mu \mathrm{m}$ thick, Jee, 1983) could be resolved with one element. This gave a mesh of 14,698 four-node linear quadrilateral elements. All structures were considered to be bonded to neighboring structures.

The implant and metal beads were both made of titanium, with a modulus of $114 \mathrm{GPa}$. The porous coating was modeled with two bead layers. Beads within the same layer were separated by $200 \mu \mathrm{m}$ with a $100 \mu \mathrm{m}$ separation between the first and second layers. These numbers were chosen based on an average pore sizc of 50-400 $\mu \mathrm{m}$ for porous coatings made of stacked balls (Cameron et al., 1973). The center nodes of neighboring bead areas were constrained to displace equally to represent the relatively large stiffness of the connected beads relative to the surrounding tissue. A penalty method was used to impose this displacement constraint (Kikuchi, 1986). In the penalty method, an artificial stiffness of $10^{p}$ will constrain the beads to have equal displacement within $10^{-p} \mathrm{~mm}$. Thus, a large artificial stiffness would represent a rigid bead to bead porous coating while a small artificial stiffness would represent a very compliant connection between beads. Since this method imposes an artificial stiffness into the problem, the penalty parameter was varied between 100.0 and $1,000,000.0 \mathrm{~N} \mathrm{~mm}^{-1}$ to study the sensitivity of the predicted results to this parameter.

The tissue domain surrounding the implant and porous coating was separated into three distinct sections: cortical bone, trabecular bone outside the interface region, and the initial woven bone/fibrous tissue which filled the interface region. The initial woven bone/fibrous tissue was calculated from homogenization analysis of a microstructural model and input as a data file to the optimization program (Suzuki and Kikuchi, 1990). The stiffness ranged in a nonlinear manner (Bensoe and Kikuchi, 1988) from $1 \mathrm{GPa}$ at $100 \%$ hard tissue volume fraction to less than $1 \mathrm{MPa}$ at $1 \%$ hard tissue volume. The material in the design

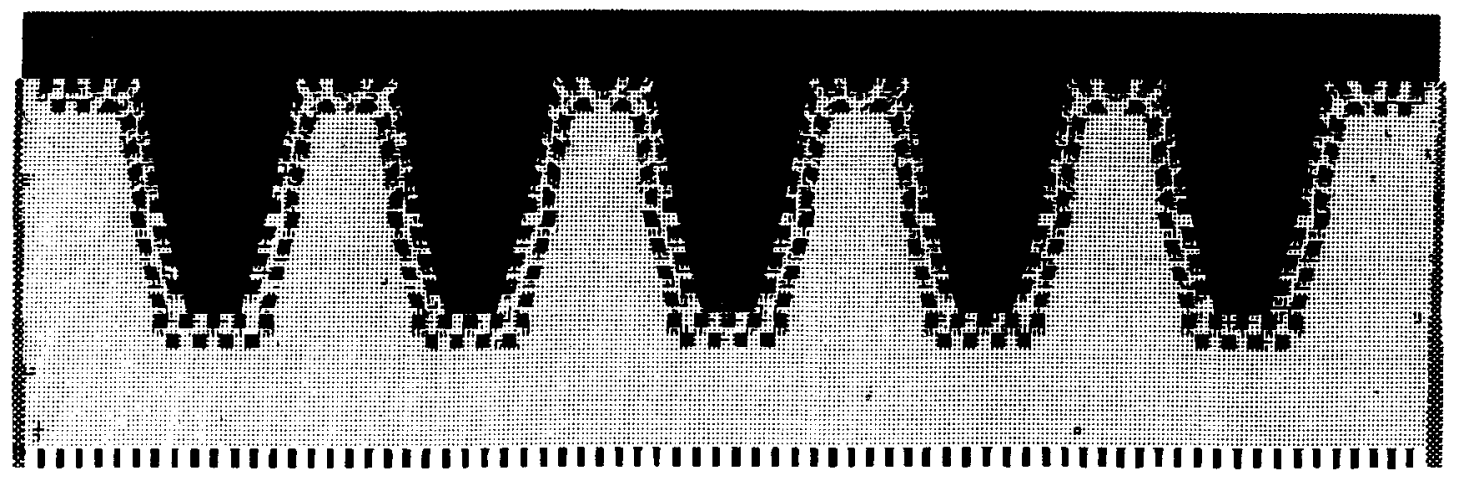

\author{
Implant Interface Model Geometry \\ Implant \& Porous Coating \\ Initial Design Area \\ Cortical Shell \\ Trabecular Boundary
}

Fig. 1. Geometry of the finite element model of the implant-bone interface. The implant and porous coating, the initial design area, the cortices, and the trabecular bone boundary represented by the struts at the bottom of the model are shown. The model contained 14,698 four-node quad elements (not shown). The total strain energy in the implant interface model was calculated using the finite element model at each iteration of the optimization process. 
domain will have cubic symmetry based on the assumed microstructure for the initial homogenization analysis (Suzuki and Kikuchi, 1990). The stiffness of this material is updated during iterative solution of the optimization problem based on the current volume fraction and material orientation.

The cortical bone tissue was assumed to vary in thickness from 0.3 to $0.5 \mathrm{~mm}$ and behave as a linearly elastic isotropic material. The assumed cortical bone stiffness was varicd from 2 to $15 \mathrm{GPa}$, since this stiffness will determine how much of the implant load is carried by trabecular bone and how much is carried by cortical bone. Trabecular bone outside of the interface region (which will be called the trabecular boundary) was modeled as thin struts $(200 \mu \mathrm{m}$ is width) supported by elastic springs, which represented the stiffness of the surrounding trabecular bone. The struts were assumed to be isotropic with a Young's modulus of $5 \mathrm{GPa}$ and a Poisson's ratio of 0.2 . The struts attached directly to the elements of the design area. The springs were attached to the base of the struts. The spring stiffiness values for the trabecular boundary sensitivity study were varied from 100 to 500 to $1000 \mathrm{~N} \mathrm{~mm}^{-1}$. Both the cortical bone and the trabecular bone struts outside the interface region were fixed and not allowed to change during the optimization process. The initial bone/fibrous tissue in the interface regions was defined as the design domain for the optimization process. The final material constraint was set at $30 \%$ hard tissue volume fraction for all cases unless stated otherwise.

Assumed loading conditions may also significantly affect the predicted topology. The sensitivity of the predicted results to assumed loading conditions was

$\mathbf{A}$

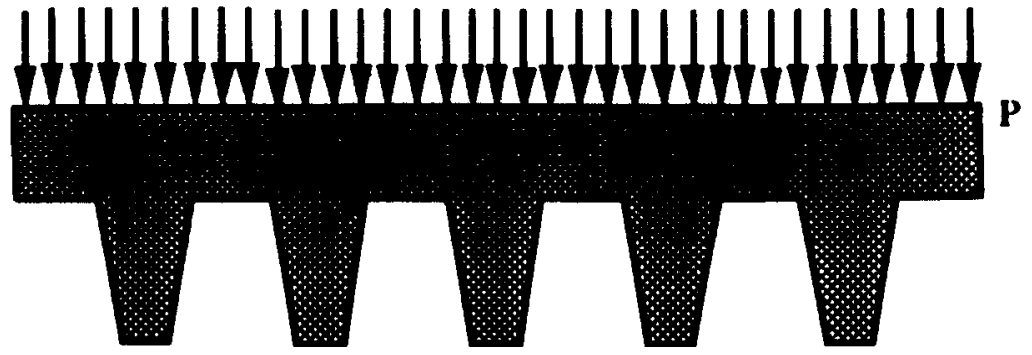

Uniform Uniaxial Load

A

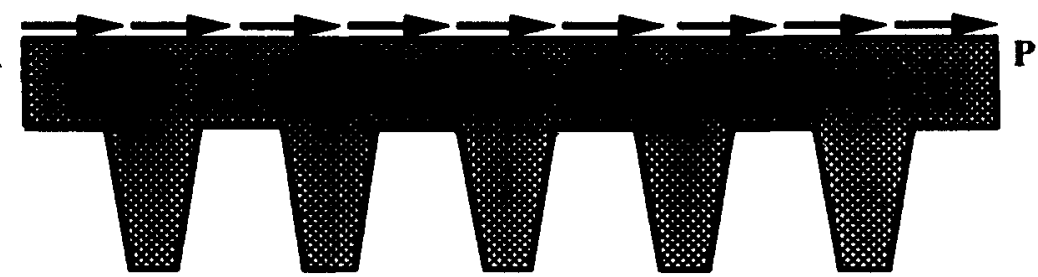

Single Shear Load of the Multiple Loading Case

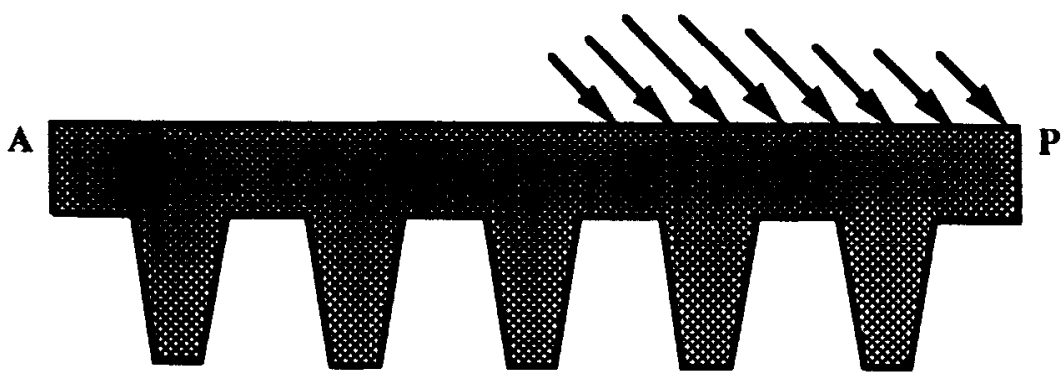

Posterior Directed Load

Fig. 2. Cases used to test the sensitivity of predicted results to different loading conditions. $P$ denotes the posterior part of the implant and A denotes the anterior portion. Three loading cases were tested: (1) a uniform uniaxial single loading condition (top); (2) a multiple load case containing the uniform uniaxial load case plus two shear loading conditions of the same magnitude with opposite directions (of which only one is shown) (middle); and (3) a single load condition of a posteriorly directed $45^{\circ}$ load component containing both axial and shear load components (bottom). 
assessed using three loading conditions: (1) a uniform axial loading; (2) a multiple loading case with separate axial and shear loads; and (3) a combined posteriorly directed axial and shear loading (Fig. 2). The uniform axial load and multiple loading case were applied across the entire implant while the posterior load case was only applied over the posterior half of the implant. The posterior load was chosen to represent loading which may result from the primarily flexed position of the canine leg. For multiple load cases, the optimization program calculates the load which produces the maximum SED at each iteration and optimizes the structure with respect to this load. In all cases, the total magnitude of each load vector was set to $1.0 \mathrm{~N}$.

There are two assumptions relative to the optimization formulation which may affect the predicted results: (1) initial material distribution and (2) the material constraint. The initial material distribution refers to the density distribution of the woven bone/fibrous tissue material chosen to begin the optimization analysis. The material constraint is the total amount of material which is allowed within the design area. The initial density is used by the program to calculate an initial stiffness at each point in the design domain. Since there is no guarantee that the program will find a global minima, it is possible that the initial material density of a uniform material distribution may influence the predicted material distribution. Uniform initial material distribution that equaled 87,97 , and $147 \%$ of the $30 \%$ material constraint, effectively 26.1 , 29 , and $44 \%$ initial hard tissue volume fraction, were studied to see if these assumptions would affect the final material distribution. These material volume fractions would produce effective moduli essentially in the range of compliant trabecular bone. Material constraints that were between 24 and $54 \%$ of the total design area were studied in increments of $6 \%$ to determine the effect of this parameter on the final material distribution. The sensitivity in each case was determined by comparing the plot of tinal material distribution and the global SED value.

\section{Comparison to experimental results}

Two measurements of bone adaptation (using backscattered SEM) were made in the experimental study reported by Goldstein et al. (1991b). First, the percentage of bone ingrowth was defined as the area of bone tissue per area available for bone ingrowth within the beaded region. Second, the percentage apposition was defined as the amount of bone tissue per available area from the outer edge of the porous coating to a distance 200-300 microns away from the porous coating. The finite element model was subdivided into 11 and 31 regions (Fig. 3) in which the percentage ingrowth and apposition were calculated. These quantities were then compared with the corresponding locations from implant histological sections of a 9- and a 12-month animal. The results from the 9-and 12-month animals were pooled and compared with the predicted results using standard linear regression. The predicted results from the three loading conditions (material constraint fixed at $30 \%$ ) and the cases with different final material constraints (under a fixed uniaxial load) were compared with the experimental results. For each
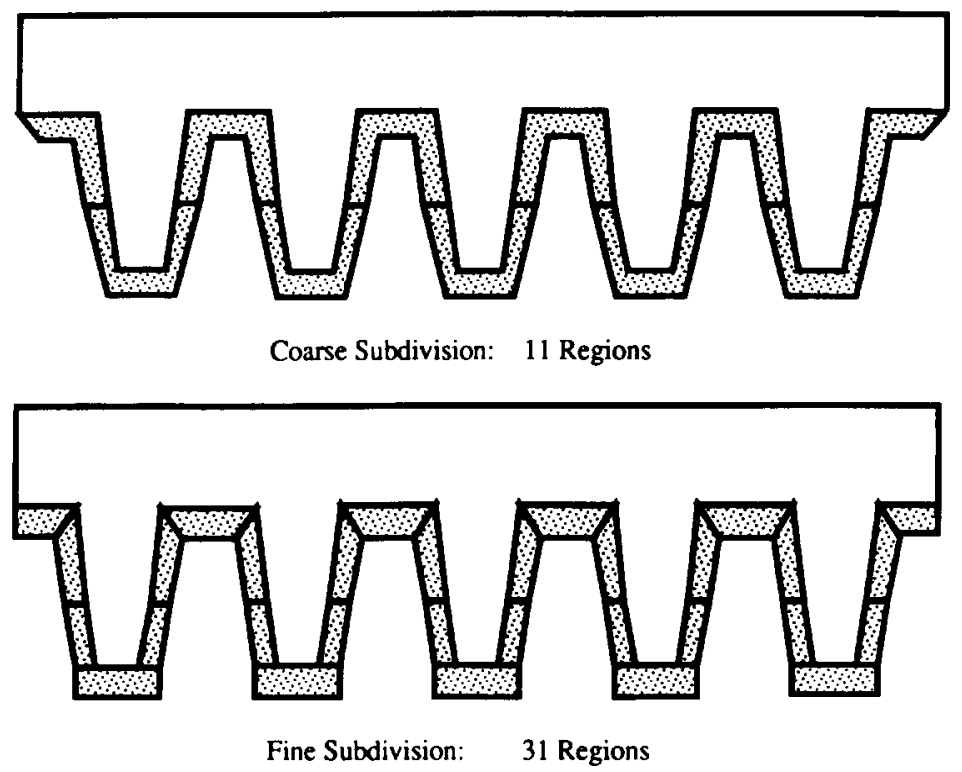

Fig. 3. Regions along the implant interface for which both bone ingrowth and bone apposition were calculated for both the experimental and computational cases. The coarse subdivision of 11 regions (top) was used to examine how well the program predicted general locations of bone ingrowth and apposition. The fine subdivision of 31 regions (bottom) was used to examine how well the program predicted specific locations of bone ingrowth and apposition. In each case, the shaded areas are the regions where bone ingrowth and apposition were calculated and the blank region is the implant outline. 
experimental comparison the cortical bone stiffness was $5 \mathrm{GPa}$ and the trabecular houndary stiffness was chosen to be $500 \mathrm{~N} \mathrm{~mm}^{-1}$.

\section{RESULTS}

\section{Sensitivity study}

Changing the cortical bone stiffness from 2 to $15 \mathrm{GPa}$ did not alter significantly either the predicted material distribution or the final SED value (Fig. 4). The topology optimization predicted material at the cone tips, with a very small amount of material at the intersection of the implant and the cortical shell. For the rest of the studies, the cortical bone stiffness was kept at $5 \mathrm{GPa}$.
Assuming the trabecular boundary spring stiffness to be 500 or $1000 \mathrm{~N} \mathrm{~mm}^{-1}$ had no significant effect on the predicted material distribution or on the final SED value (Fig. 5). However, changing the trabecular boundary stiffness to $100 \mathrm{~N} \mathrm{~mm}^{-1}$ produced a more porous bone near the cone tips, thickened the cortical shell, and doubled the final SED value (Fig. 5). Since the boundary was more compliant, the program sought a stiffer structure by placing more material near the cortical shell to transfer load from the implant to the cortical shell.

Under uniform axial loading, a dense apposition of bone was predicted under the cone tips (Fig. 6). The application of a shear load significantly changed the direction of bone apposition, producing struts oriented at approximately $45^{\circ}$ (Fig. 6), and greatly increased

Final SED $=2.43$

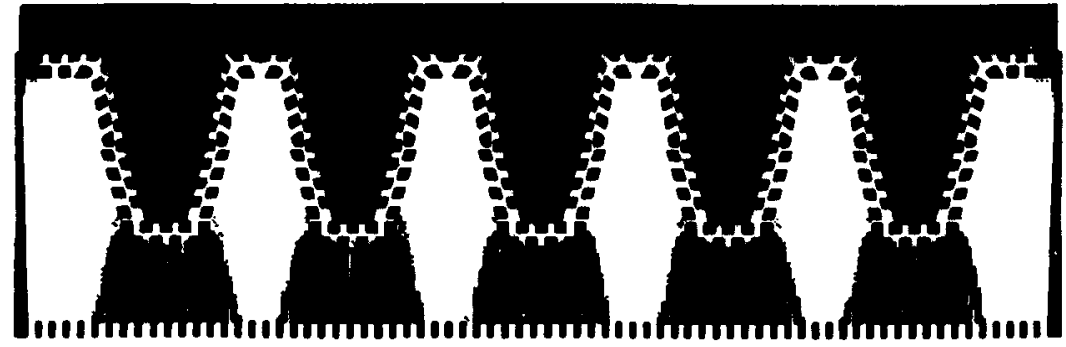

Cortical Bone Stiffness: $15 \mathrm{GPa}$

Final SED $=2.78$

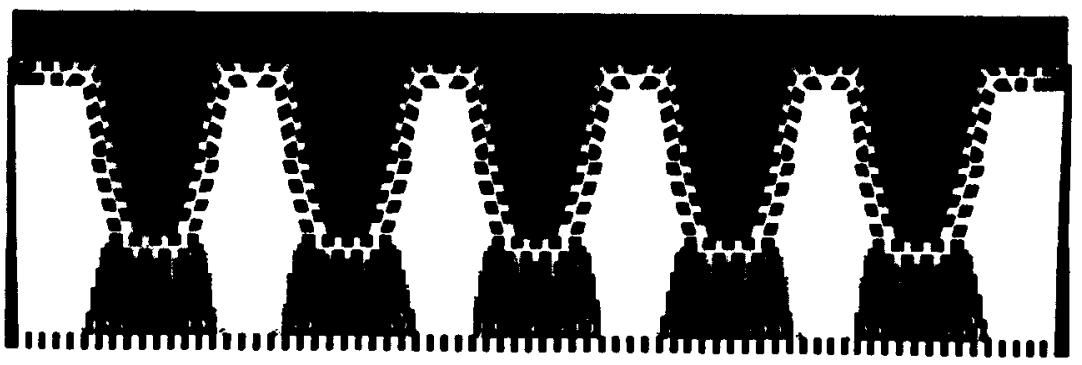

Cortical Bone Stiffness: 5 GPa

Final SED $=2.59$

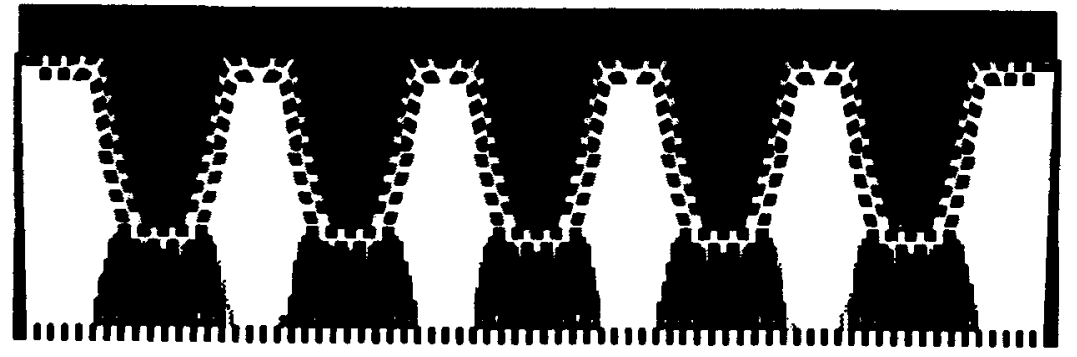

Cortical Bone Stiffness: 2 GPa

Fig. 4. Effect of cortical bone stiffness on predicted material distribution. Results for cortical bone stiffness of $15 \mathrm{GPa}$ (top), $5 \mathrm{GPa}$ (middle), and $2 \mathrm{GPa}$ (bottom) are shown. Changing the cortical bone stiffness had almost no effect on the final predicted material distribution. All cases were subject to a uniaxial load and had a trabecular boundary stiffness of $500 \mathrm{~N} \mathrm{~mm}^{-1}$ and an artificial bead-to-bead contact stiffness of $1,000,000 \mathrm{~N} \mathrm{~mm}^{-1}$. The volume constraint in each case was set to $30 \%$ of the total design area. All SED values are in $\mathrm{J} \mathrm{mm}^{-2}$. 
the global SED. The posteriorly directed load also changed the direction of bone apposition (Fig. 6) and increased the final global SED. In each case, however, the bone apposition and ingrowth occurred predominantly at the cone tips. The amount of ingrowth drastically decreased when shear loading was applied to the implant.

The overall ingrowth and apposition patterns did not change when the penalty parameter constraining the bead centers was changed from $10,000.0$ to $1,000,000.0 \mathrm{~N} \mathrm{~mm}^{-1}$ (Fig. 7). When the penalty parameter was reduced to 100.0 the amount of ingrowth slightly increased, but otherwise the overall material distribution patterns did not change (Fig. 7). Decreasing the penalty parameter only slightly increased the overall final SED.

The final predicted material distribution was nearly identical for the three cases of different initial material densities. Bone apposition and ingrowth were again predicted primarily around the cone tips. The final global SED changed very little, ranging from $2.60 \mathrm{~J} \mathrm{~mm}^{-2}$ for the $87 \%$ case to $2.86 \mathrm{~J} \mathrm{~mm}^{-2}$ for the $147 \%$ case. These results show that the global optimization scheme will produce the same structure regardless of the initial material density, given that the initial distribution of material is the same. In other words, a

Final SED $=2.73$

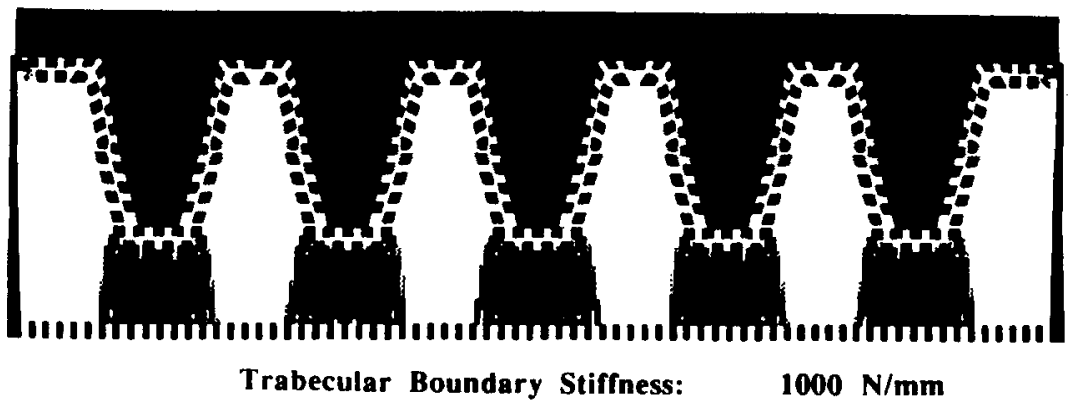

Final SED $=2.78$

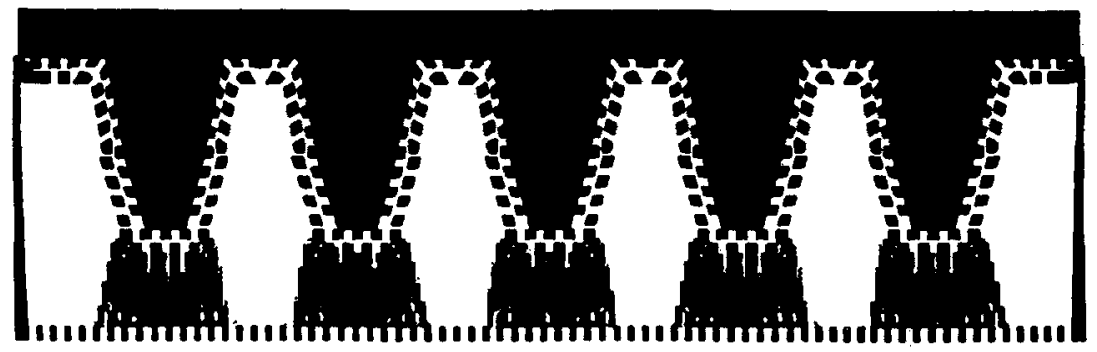

Trabecular Boundary Stiffness: $\quad 500 \mathrm{~N} / \mathrm{mm}$

Final SED $=4.19$

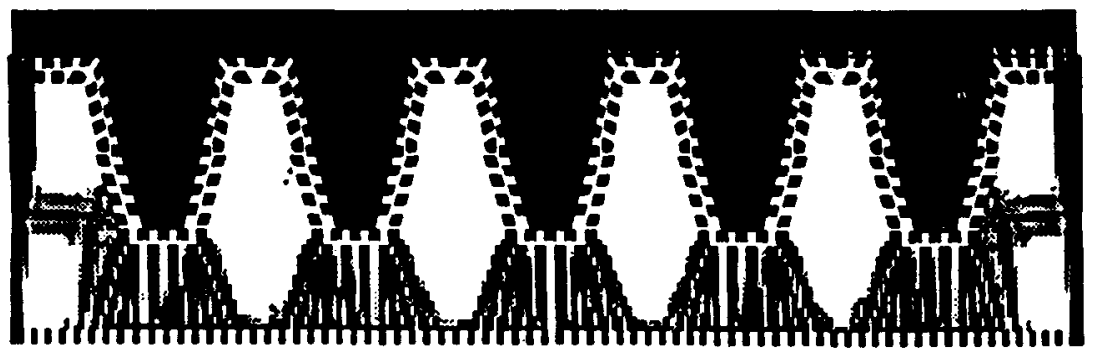

Trabecular Boundary Stiffness: $\quad 100 \mathrm{~N} / \mathrm{mm}$

Fig. 5. Effect of trabecular boundary stiffness on predicted material distribution. Results for trabecular boundary stiffness of $1000 \mathrm{~N} \mathrm{~mm}^{-1}$ (top), $500 \mathrm{~N} \mathrm{~mm}^{-1}$ (middle), and $100 \mathrm{~N} \mathrm{~mm}^{-1}$ (bottom) are shown. Changing the boundary stiffness from 1000 to $500 \mathrm{~N} \mathrm{~mm}^{-1}$ had no effect on the predicted material distribution. Changing the boundary stiffness to $100 \mathrm{~N} \mathrm{~mm}^{-1}$ produced a significantly more porous material distribution. All cases were subject to a uniaxial load and had a cortical bone stiffness of $5 \mathrm{GPa}$ and an artificial bead-to-bead contact stiffness of $1,000,000 \mathrm{~N} \mathrm{~mm}^{-1}$. The volume constraint in each case was set to $30 \%$ of the total design area. All SED values are in $\mathrm{J} \mathrm{mm}^{-2}$. 
Final SED $=2.78$

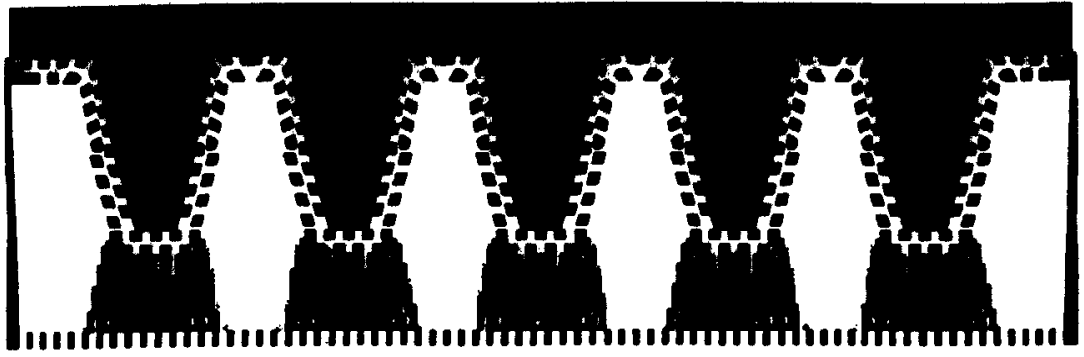

Uniform Axial Load

Final SED $=19.43$

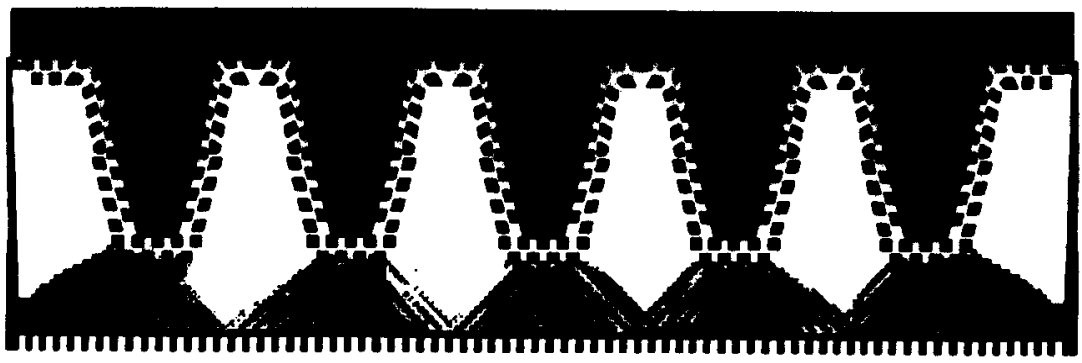

Multiple Load Case: Separate Axial and Shear Loads

Final SED $=18.15$

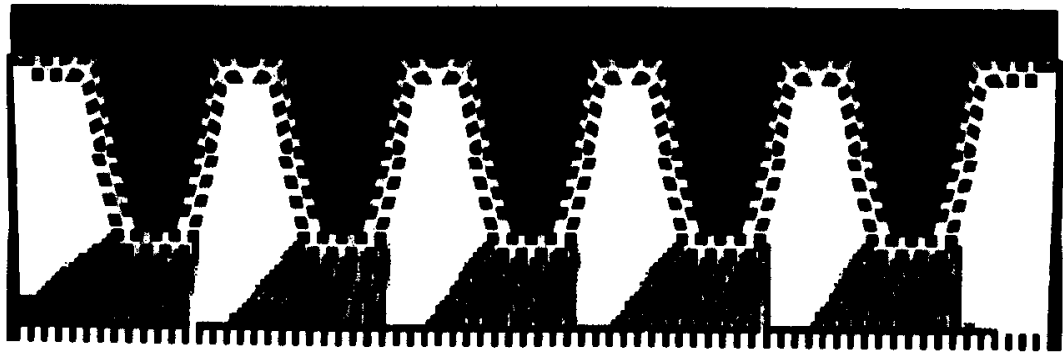

Posterior Directed Axial plus Shear Load

Fig. 6. Effect of loading conditions on predicted material distribution. Results for a uniaxial load (top), multiple load case with separate axial and shear loads (middle), and a posteriorly directed axial plus shear loading (bottom) are shown. The uniform axial load produces a consolidated bone material at the cone tip oriented longitudinally. Application of any shear load component drastically changed the orientation of the material, but the majority of bone apposition and ingrowth remained at the cone tips. The results suggest that implant shape may be a major determinant of the location of bone apposition and ingrowth. All cases had a cortical bone stiffness of $5 \mathrm{GPa}$, a trabecular boundary stiffness of $500 \mathrm{~N} \mathrm{~mm}^{-1}$ and an artificial beadto-bead contact stiffness of $1,000,000 \mathrm{~N} \mathrm{~mm}^{-1}$. The volume constraint in each case was set to $30 \%$ of the total design area. All SED values are in $\mathrm{J} \mathrm{mm}^{-2}$.

uniformly distributed material ranging from approximately 20 to $50 \%$ hard tissue volume would lead to the same globally optimized equilibrium structure. This result suggests that bone adaptation following a global optimization process would reach the same equilibrium structure regardless of initial density, at lcast within a $20-50 \%$ hard tissue volume fraction range.

Changing the material constraint is equivalent to changing the global equilibrium SED which the ingrowth tissue will reach. For the $24 \%$ material constraint, bone apposition was predicted only at the cone tip (Fig. 8). As the material constraint was increased, more bone apposition was distributed along the cone side, with some preference to putting material along the exterior cone (Fig. 8). No material was placed at the cone base for any material constraint. There was only a slight increase in bone ingrowth at the cone tip as the material constraint was increased. The final global SED decreased from $3.85 \mathrm{~J} \mathrm{~mm}^{-2}$ (at $24 \%$ ) to $1.85 \mathrm{~J} \mathrm{~mm}^{-2}$ (at $54 \%$ ) with increasing amounts of material. These results show that material placed at the cone tips is most effective for reducing deformation of the hone-implant composite. 


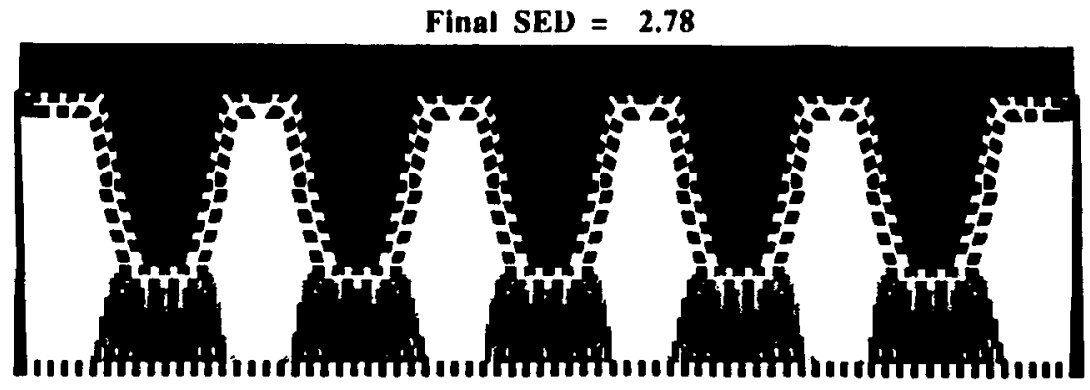

Bead to Bead Contact Stiffness: $\quad 100000 \mathrm{~N} / \mathrm{mm}$

Final SED $=2.84$

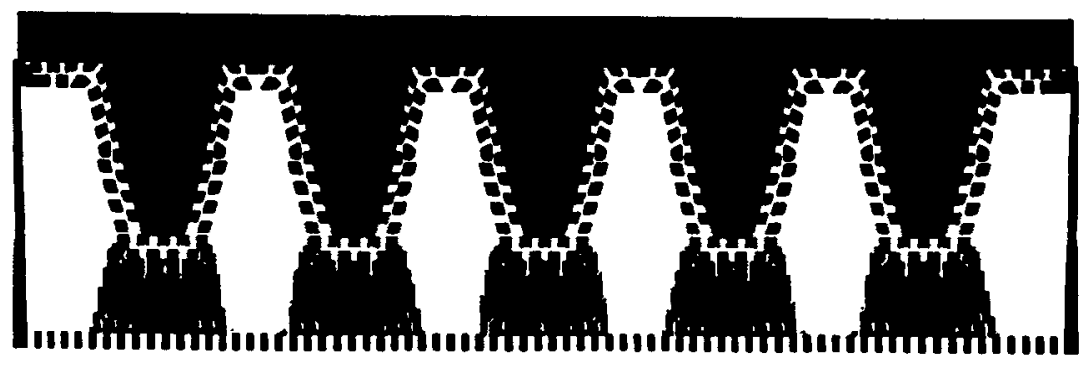

Bead to Bead Contact Stiffness: $\quad 10000 \mathrm{~N} / \mathrm{mm}$

Final SED $=3.06$

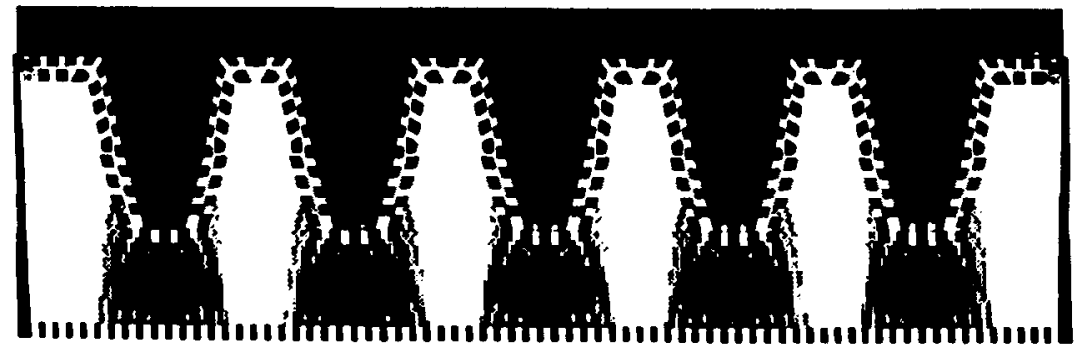

Bead to Bead Contact Stiffness: $100 \mathrm{~N} / \mathrm{mm}$

Fig. 7. Effect of the artificial bead-to-bead contact spring stiffness on predicted material distribution. Results for $1,000,000 \mathrm{~N} \mathrm{~mm}^{-1}$ (top), $10,000 \mathrm{~N} \mathrm{~mm}^{-1}$ (middle), and $10 \mathrm{~N} \mathrm{~mm}^{-1}$ (bottom) are shown. Changing the spring stiffness from $1,000,000$ to $10,000 \mathrm{~N} \mathrm{~mm}^{-1}$ did not affect the predicted results. Reducing the spring stiffness to $100 \mathrm{~N} \mathrm{~mm}^{-1}$ increased the amount of material within the porous coating (bone ingrowth). However, $100 \mathrm{~N} \mathrm{~mm}^{-1}$ may be a physically unrealistic bead spring stiffness. These results suggest that the stiffness of the porous coating may produce a stress shielding effect which limits ingrowth of bone tissue. All cases were subject to a uniaxial load and had a trabecular boundary stiffness of $500 \mathrm{~N} \mathrm{~mm}^{-1}$ and a cortical bone stiffness of $5 \mathrm{GPa}$. The volume constraint in each case was set to $30 \%$ of the total design area. All SED values are in $\mathbf{J ~ m m}^{-2}$.

\section{Comparison with experimental results}

Linear regressions were used to compare the predicted bone ingrowth to pooled results from a 9- and a 12-month animal for the three different loading conditions (Table 2). The best correlations between the predicted and the experimental results were found for the 11-region subdivision comparison. In this case, the correlation coefficients were significant for all loading cases, reflecting the fact that material apposition was predicted at the cone tip similar to the general location found experimentally. For the 31-region subdivision, the correlation coefficients between predicted and experimental results were not significant. This low correlation results because the program predicts a lumped mass of material only at the cone tips while bone in the experiment was found fairly evenly distributed along the cone tips and the distal end of the cones.

The statistical significance of the correlations, defined as $R^{2}>0.5$, between predicted and experimental ingrowth for both the 11- and 31-region comparisons 


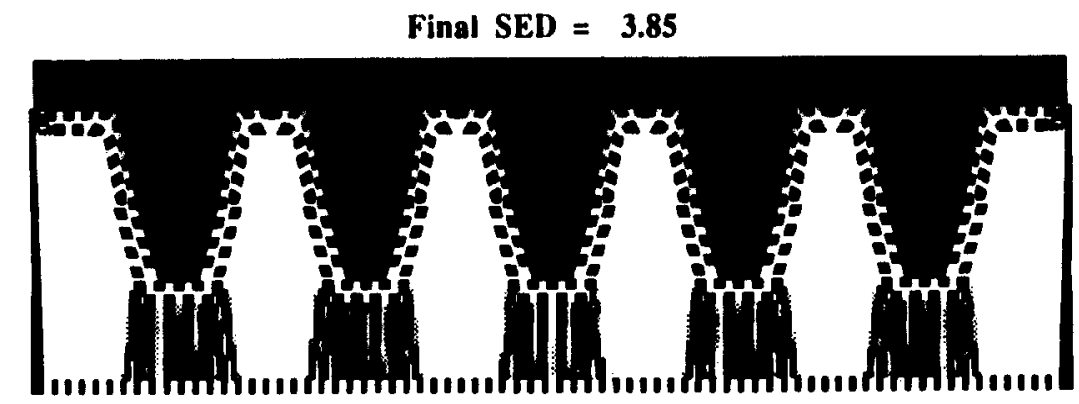

Material Constraint: $24 \%$ of Total Design Area

Final SED $=2.78$

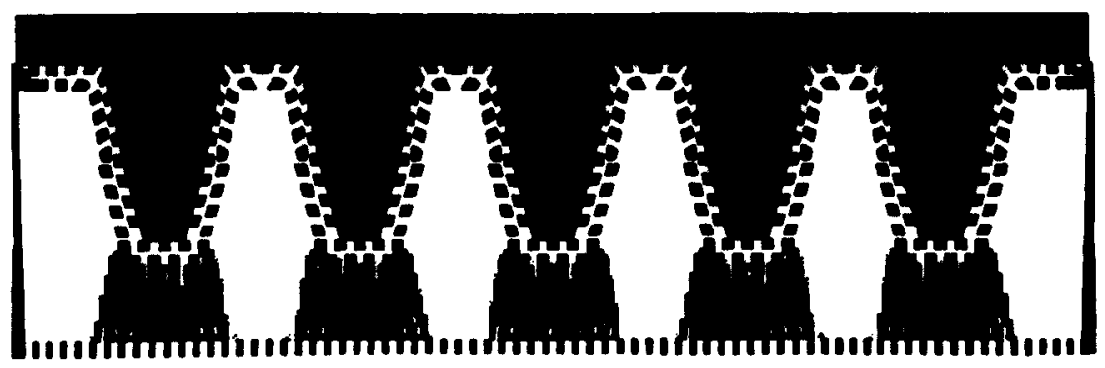

Material Constraint: $30 \%$ of Total Design Area

Final SED $=1.85$

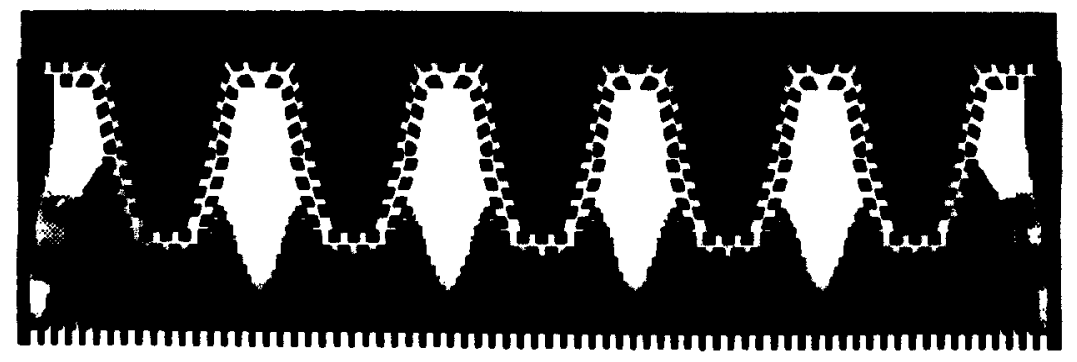

Material Constraint: $54 \%$ of Total Design Area

Fig. 8. Effect of final material constraint on predicted material distribution. Results for constraints of $24 \%$ (top), 30\% (middle), and 54\% (bottom) of the total design area are shown. With increasing material constraint, more material is predicted along the sides of the cone as well as spreading out along the trabecular boundary. The predilection for material at the cone tips indicates that this area is most significant for producing a maximally stiff bone-implant composite. All cases were subject to a uniaxial load and had a trabecular boundary stiffness of $500 \mathrm{~N} \mathrm{~mm}^{-1}$ and a cortical bone stiffness of $5 \mathrm{GPa}$. All SED values are in $\mathrm{J} \mathrm{mm}^{-2}$.

was not changed by choice of final material constraint. although there was a change in some $R^{2}$ values (Table 3). Correlations between the predicted and experimental apposition for the 11-region comparison showed a slight improvement as the final material constraint increased, while the apposition correlations for the 31-region comparison showed a substantial increase as the amount of material in the design domain increased, but still did not reach significance. The improved correlation for the 31-region apposition reflects the increasing amount of material predicted along the sides of the cones. This increased material apposition corresponded more closely with experimental results (Fig. 9).

\section{DISCUSSION}

Comparisons between predicted and experimental results suggest that bone ingrowth and apposition may be distributed in areas where it is best suited to support the implant under load. This premise is supported by both human retrieval and animal studies (Table 1) which all report ingrowth on fixation pegs for tibial, acetabular, and distal femoral components, but 
Table 2. Linear regression equation Experimental $=A+B *$ Predicted as well as the $R^{2}$ values for the comparison between predicted and experimental bone ingrowth and apposition for the three different loading conditions. The number $n$ is the total number of interface regions analyzed. Results for both the 32- and 11-region subdivisions are shown. The predicted results explain little of the variance for the 32-region subdivision. The predicted results explain much more of the variance for the 11-region subdivision, except for the multiple loading case, which shows poor correlation with the experimental ingrowth results

\begin{tabular}{llcccccc}
\hline Loading conditions & Quantity & Regions & $\boldsymbol{R}^{\mathbf{2}}$ & $A$ & $\boldsymbol{B}$ & $n$ & $p$ \\
\hline Uniform axial & Ingrowth & 31 & 0.13 & 1.3 & 15.3 & 62 & $<0.01$ \\
Multiple load case & Ingrowth & 31 & 0.01 & 2.8 & 16.9 & 62 & $<0.01$ \\
Posterior directed & Ingrowth & 31 & 0.12 & 1.6 & 15.5 & 62 & $<0.01$ \\
Uniform axial & Apposition & 31 & 0.26 & 0.6 & 16.7 & 62 & $<0.01$ \\
Multiple load case & Apposition & 31 & 0.17 & 0.6 & 19.4 & 62 & $<0.01$ \\
Posterior directed & Apposition & 31 & 0.22 & 0.5 & 18.3 & 62 & $<0.01$ \\
Uniform axial & Ingrowth & 11 & 0.59 & 3.8 & 1.1 & 22 & $<0.01$ \\
Multiple load case & Ingrowth & 11 & 0.02 & 1.2 & 14.2 & 22 & $<0.01$ \\
Posterior directed & Ingrowth & 11 & 0.33 & 3.4 & 3.6 & 22 & $<0.01$ \\
Uniform axial & Apposition & 11 & 0.68 & 1.3 & 4.7 & 22 & $<0.01$ \\
Multiple load case & Apposition & 11 & 0.59 & 1.8 & 2.9 & 22 & $<0.01$ \\
Posterior directed & Apposition & 11 & 0.72 & 1.4 & 3.8 & 22 & $<0.01$ \\
\hline
\end{tabular}

Table 3. Correlation between predicted and experimental results for bone ingrowth and apposition with increasing material constraint. The coefficients of the linear regression equation Experimental $=A+B *$ Predicted are shown for $n$ interface region comparisons. Ingrowth correlations show no significant change with increasing material constraint for either the 11- or 32region comparison. Apposition correlation improves with increasing material constraint for the 32-region comparison, reflecting an increased amount of material predicted along the cone side. Apposition correlation increases slightly for 11-region comparison

\begin{tabular}{|c|c|c|c|c|c|c|c|}
\hline Material constraint & Quantity & Regions & $R^{2}$ & $A$ & $B$ & $n$ & $p$ \\
\hline $24 \%$ of design area & Ingrowth & 31 & 0.14 & 15.2 & 1.44 & 62 & $<0.01$ \\
\hline $30 \%$ of design area & Ingrowth & 31 & 0.13 & 15.3 & 1.30 & 62 & $<0.01$ \\
\hline $36 \%$ of design area & Ingrowth & 31 & 0.14 & 16.1 & 0.59 & 62 & $<0.01$ \\
\hline $42 \%$ of design area & Ingrowth & 31 & 0.13 & 16.1 & 0.52 & 62 & $<0.01$ \\
\hline $48 \%$ of design area & Ingrowth & 31 & 0.13 & 16.1 & 0.51 & 62 & $<0.01$ \\
\hline $54 \%$ of design area & Ingrowth & 31 & 0.15 & 15.6 & 0.48 & 62 & $<0.01$ \\
\hline $24 \%$ of design area & Apposition & 31 & 0.14 & 21.1 & 0.45 & 62 & $<0.01$ \\
\hline $30 \%$ of design area & Apposition & 31 & 0.26 & 16.6 & 0.60 & 62 & $<0.01$ \\
\hline $36 \%$ of design area & Apposition & 31 & 0.25 & 17.0 & 0.46 & 62 & $<0.01$ \\
\hline $42 \%$ of design area & Apposition & 31 & 0.32 & 14.7 & 0.47 & 62 & $<0.01$ \\
\hline $48 \%$ of design area & Apposition & 31 & 0.42 & 10.5 & 0.54 & 62 & $<0.01$ \\
\hline $54 \%$ of design area & Apposition & 31 & 0.46 & 8.0 & 0.54 & 62 & $<0.01$ \\
\hline $24 \%$ of design area & Ingrowth & 11 & 0.58 & 1.0 & 3.85 & 22 & $<0.01$ \\
\hline $30 \%$ of design area & Ingrowth & 11 & 0.59 & 1.2 & 3.79 & 22 & $<0.01$ \\
\hline $36 \%$ of design area & Ingrowth & 11 & 0.57 & 1.8 & 1.63 & 22 & $<0.01$ \\
\hline $42 \%$ of design area & Ingrowth & 11 & 0.57 & 1.2 & 1.51 & 22 & $<0.01$ \\
\hline $48 \%$ of design area & Ingrowth & 11 & 0.56 & 0.9 & 1.50 & 22 & $<0.01$ \\
\hline $54 \%$ of design area & Ingrowth & 11 & 0.53 & 1.9 & 1.20 & 22 & $<0.01$ \\
\hline $24 \%$ of design area & Apposition & 11 & 0.67 & 4.4 & 1.90 & 22 & $<0.01$ \\
\hline $30 \%$ of design area & Apposition & 11 & 0.69 & 4.7 & 1.36 & 22 & $<0.01$ \\
\hline $36 \%$ of design area & Apposition & 11 & 0.69 & 4.8 & 1.03 & 22 & $<0.01$ \\
\hline $42 \%$ of design area & Apposition & 11 & 0.71 & 4.7 & 0.87 & 22 & $<0.01$ \\
\hline $48 \%$ of design area & Apposition & 11 & 0.72 & 2.8 & 0.79 & 22 & $<0.01$ \\
\hline $54 \%$ of design area & Apposition & 11 & 0.74 & 0.2 & 0.76 & 22 & $<0.01$ \\
\hline
\end{tabular}

report none or varied amounts of ingrowth at the plates or trays of these components. The consistent finding of ingrowth on or around the fixation pegs indicates that bone ingrowth on the pegs may contribute most to mechanical stability of the implant. This conclusion is suggested by the sensitivity study on material constraint which showed material first placed at the cone tip, followed by material being placed along the sides of the cone. The component tray is the last location at which the optimization program places material, except at the point where the tray intersects the cortical shell. This parallels the finding in the literature that ingrowth on the tray has been reported to range from none to limited amounts at specific locations on the tray, including the point at which the tray contacts the cortical shell in tibial components. The correspondence between experimental and predicted results suggests that bone cells 

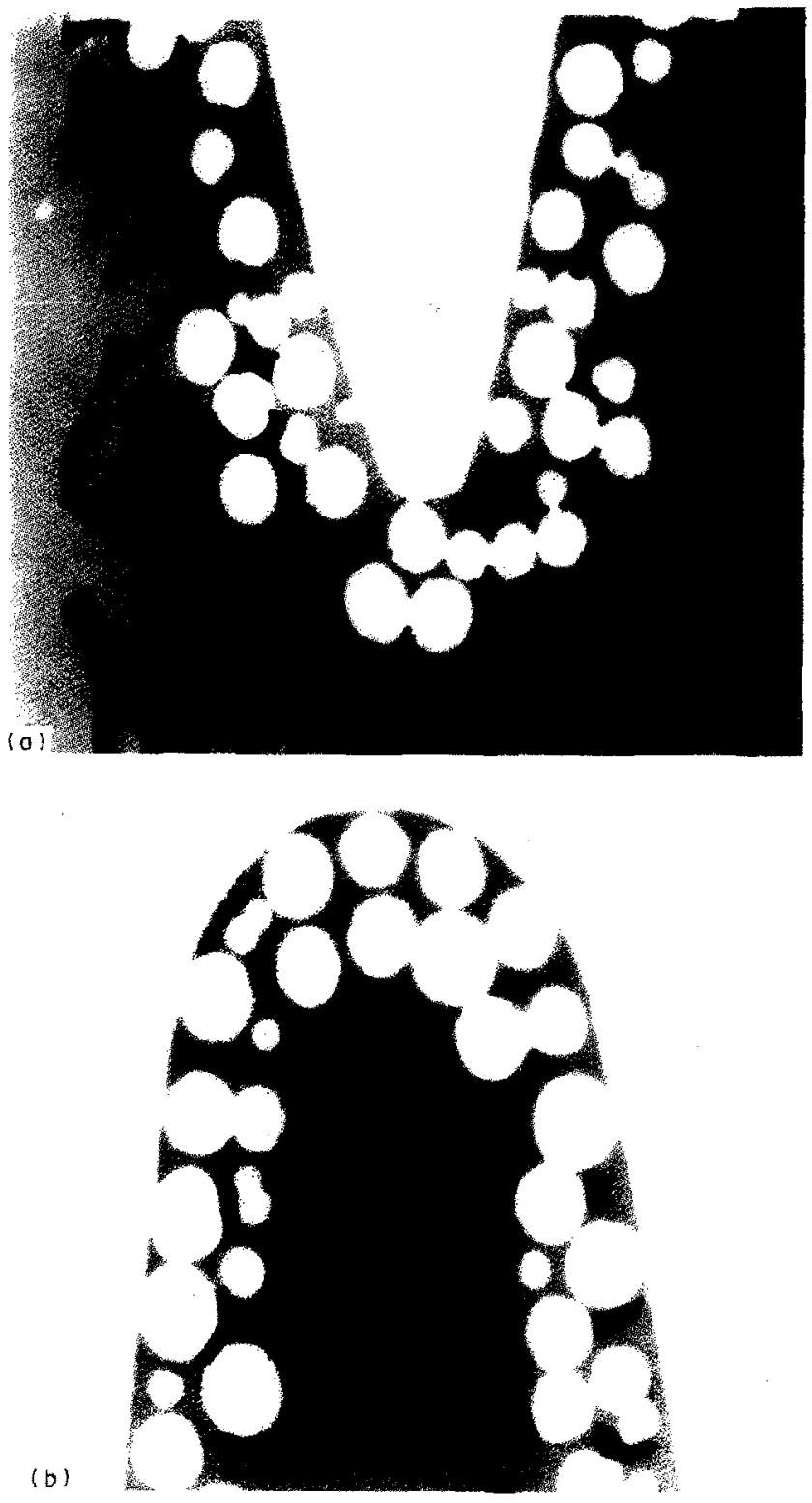

Fig. 9. Experimentally measured ingrowth and apposition at the tip of a cone (a) (one-half cone length) and at the base of the cone (b) (one-half cone length) from a 12-month animal (Goldstein et al., 1991). The location of bone apposition and ingrowth, i.e. bone at the cone tip and no bone at the cone base, agrees with predicted results. This suggests that bone adaptation processes may be seeking to attain some mechanical objective. However, the difference between the porous bone structure measured experimentally and the predicted consolidated bone mass suggests that bone adaptation to porous coated implants may be driven by a local mechanical objective or perhaps a combination of mechanical and cell nutritional objectives. 
do model and remodel tissue around implants such that it is attains some mechanical objective, as has also been suggested by other investigators (Huiskes et al., 1987; Orr et al.,1990).

The specific topology of bone apposition and ingrowth, however, was not precisely predicted by the topology optimization program. Specifically, the topology optimization program predicted a dense consolidated mass of bone at the cone tips for each case analyzed while the experimental study by Goldstein et al. (1991b) showed more porous trabecular bone distributed at the cone tips and around the distal sides of the cones. One explanation is that bone adaptation around porous coated implants may correspond more closely to a local optimization procedure. However, differences between local and global optimization procedures may not be large enough to explain the discrepancy between predicted and experimental results since a global objective is a volumeweighted average of local variables. Thus, areas of high stress would most likely lead to some degree of material densification in both local and global formulations while areas of low stress would be sites of material resorption in both formulations.

Perhaps a more plausible explanation for the porosity of bone surrounding the implant is the manner in which osteocytes within trabeculae receive nutrition. Unlike cortical bone, trabeculae rarely contain haversian systems and the osteocytes within trabeculae must receive nutrition by diffusion. It is generally believed that the need for diffusion normally limits most trabeculae to a thickness of $200 \mu \mathrm{m}$ (Jee, 1983). We hypothesize that bone cells within trabeculae responding to combined nutritional and structural needs may first produce a distributed network of discrete trabeculae surrounding the cone tip and sides rather than a consolidated mass of bone at the cone tip. Optimizing bone structure solely in response to a global objective produced a thick, corticalized structure over $1000 \mu \mathrm{m}$ thick which would require a haversian system to bring nutrition to bonc cclls. Such a thick, corticalized bone was not observed in the experiment by Goldstein et al. (1991b).

An intriguing result is the small amount of ingrowth predicted in each analysis except for the case where the penalty parameter was set to 100.0 . The magnitude of the penalty parameter is related to the porous coating stiffness since a larger penalty parameter will limit bead displacement simulating a stiff porous coating relative to the surrounding bone. The predicted results suggest that the amount of bone ingrowth may be related to the stiffness of the porous coating. A stiff porous coating transfers most of the load from the implant substrate to the surrounding tissue, effectively stress shielding any tissue which may be within the porous coating. Any bone which is placed within the porous coating due to an injury response may be resorbed over time due to stress shielding within the porous coating. Pederson et al. (1991) postulated a similar stress shielding phenomena, finding that the highest bone stresses occurred at the outer wire layer in a Sulmesh wire coating. They stated that virtually all load was transferred from the substrate through the coating to the surrounding host bone. Ko et al. (1992) also found that stresses were concentrated at the outer bead-tissue interface in localized models of porous coating.

The present formulation differs from both time evolution models of trabecular bone remodeling (Beaupre et al., 1990a,b; Huiskes et al., 1987) and self optimization models (Carter et al., 1989; Fyhrie and Carter, 1986, 1990; Orr et al., 1990) in two aspects. First, the present formulation is a global optimization while other formulations have primarily predicted remodeling based on a local mechanical objective. Relevant to biological mechanisms, a global optimization process would require that all osteocytes communicate their deformation state. The local optimization formulations would imply that osteocytes, or a limited collection of osteocytes, would only respond to their localized deformation state. It is known that the canaliculi of different osteocytes and bone lining celis do connect via gap junctions (Cowin et al., 1991), but it is not known if any information concerning meclianical environment is communicated. It is possible that the actual adaptation process lies between a local and global process in that osteocytes communicate information about mechanical environment within a limited range.

The second important difference between the present formulation and others is that the present formulation adapts material layout by altering both the density and orientation of a specific microstructure. Previous time evolution (Beaupre et al., 1990a,b; Huiskes et al., 1987) and self-optimization models (Fyhrie and Carter, 1986, 1990; Orr et al., 1990) adapt material layout by altering density according to an empirical law which relates an isotropic Young's modulus to apparent density. For the current formulation, global SED and stiffness is affected by altering both density and orientation while in previous formulations global SED and stiffness would only be affected by altering density. The ability to orient microstructure may significantly affect the predicted material layout. Bendsoe and Kikuchi (1988) found more continuous structures when rotation was allowed but found discrete beam-like structures when no rotation was allowed. Fyhrie and Hollister (1990a, b) also found that allowing for microstructural rotation produced significantly different structures using a local microstructural-based adaptation algorithm. In a treatise on mathematical aspects of structural optimization, Kohn (1990) stated that optimization formulations which are fully relaxed, in other words, based on specific composite microstructures, will contain fewer local minima than other formulations. The relationship of the mathematical sensitivities of different adaptation formulations relative to actual biological processes needs further investigation.

Of all the physical parameters, the predicted results were most sensitive to applied boundary conditions. Carter et al. (1989) noted that their remodeling solu- 
tions were very sensitive to applied loading conditions. They found that a small number of loading conditions would produce very large gradients in predicted bone density which would be reduced as the number of loading cases increased. Thus, with any adaptation simulation it is important to test multiple load conditions to see a range of solutions unless the exact loading condition is known.

Despite some variation in material layout due to differing boundary conditions, most material apposition occurred at the cone tips regardless of assumptions about physical parameters. Furthermore, with increasing tinal material constraint, material apposition started at the cone tip and continued along the cone sides. Both these results suggest that implant shape was a major determinant of material distribution. Retrieval and animal studies (Bobyn et al., 1982; Cook et al., 1988, Hedley et al., 1982; Sumner et al., 1989; Turner et al., 1989) which show the majority of bone apposition and ingrowth at the tips of pegs and stems again support this premise. In a similar application of topology optimization, Hollister et al. (1991b) found that predicted patterns bone apposition changed significantly when the number of protrusions (either pegs or cones) was reduced from five to two.

The three conclusions of this paper that (1) bone adaptation is not solely a global optimization process, (2) the porous coating stiffness may stress-shield initially ingrown tissue, and (3) implant shape significantly affects bone adaptation are stated within the limitations of a two-dimensional analysis. It is possible that the actual three-dimensional topology of the porous coating may influence material layout differently than a two-dimensional analysis with artificially imposed stiffness. Furthermore, the actual microscopic contact conditions between the bead surfaces and the ingrown tissue may not be rigidly bonded as assumed in the present study. This assumption may also influence the final predicted material layout. The general correlations do suggest, however, that the approach of modeling a limited interface zone, perhaps in connection with other adaptation algorithms, may be useful in understanding mechanically driven bone adaptation processes around porous coated implants.

Acknowledgements - The authors gratefully acknowledge the assistance of Katsu Suzuki. We also thank Kuiwon Choi and Rick Zanecki for providing the experimental ingrowth data. Support for this study was provided by an OREF Bristol Myers Squibb/Zimmer Excellence in Research Award and the National Institutes of Health (AR20557).

\section{REFERENCES}

Beaupre, G. S., Orr, T. E. and Carter, D. R. (1990a) An approach for time-dependent bone modeling and remodeling-theoretical development. J. orthop. Res, 8, 651-661.

Beaupre, G. S., Orr, T. E. and Carter, D. R. (1990b) An approach for time-dependent bone modeling and remodeling-application: a preliminary remodeling simulation. J. orthop. Res. 8, 662-670.
Bendsoe, M. P. and Kikuchi, N. (1988) Generating optimal topologies in structural design using a homogenization method. Comp. Meth. appl. Mech. Engng 71, 192-224.

Bobyn, J. D., Cameron, H. U., Abdulla, D., Pilliar, R. M. and Weatherly, G. C. (1982) Biologic fixation and bone modeling with an unconstrained canine total knee prosthesis. Clin. Orthop. Rel. Res. 166, 301-312.

Cameron, H. U., Pilliar, R. M. and Macnab, I. (1973) The effect of movement on the bonding of porous metal to bone, J. biomed. Mater. Res. 7, 301-311.

Carter, D. R., Orr, T. E. and Fyhrie, D. P. (1989) Relationships between loading history and femoral cancellous bone architecture. J. Biomechanics 22, 231-244.

Cheal, E. J., Snyder, B. D., Nunamaker, D. M. and Hayes, W. C. (1987) Trabecular bone remodeling around smooth and porous implants in an equine patellar model. $J$. Biomechanics 11/12, 1121-1134.

Collier, J. P., Bauer, T. W., Bloebaum, R. D., Bobyn, J. D., Cook, S. D., Galante, J. O., Harris, W. H., Head, W. C., Jasty, M. J., Mayor, M. B., Sumner, D. R. and Whiteside, L. A. (1992) Results of implant retrieval from postmortem specimens in patients with well-functioning long-term total hip replacement. Clin. Orthop. Rel. Res. 274, 97-112.

Collier, J. P., Mayor, M. B., Chae, J. C., Suprenant, V. A., Suprenant, H. P. and Dauphinais, L. A. (1988) Macroscopic and microscopic evidence of prosthetic fixation with porous-coated materials. Clin. Orthop. Rel. Res. 235, $173-180$.

Cook, S. D., Barrack, R. L., Thomas, K. A. and Haddad, R. J. (1989) Quantitative histologic analysis of tissue growth into porous total knec components. J. Arthroplasty 4 (Suppl.) 33-43.

Cook, S. D., Thomas, K. A. and Haddad, R. J. (1988) Histologic analysis of retrieved human porous-coated total joint components. Clin. Orthop. Rel. Res. 234, 90-101.

Cowin, S. C., Moss-Salentijn, L. and Moss, M. L. (1991) Candidates for the mechanosensory system in bone, J, biomech. Engng 113, 191-197.

Engh, G. A., Bobyn, J. D., and Peterson, T. L. (1988) Radiographic and histologic study of porous coated tibial component fixation in cementless total knee arthroplasty. Orthopedics 11, 725-731.

Frost, H. M. (1986a) Intermediary Organization of the Skeleton Vol. I. CRC Press, Boca Raton.

Frost, H. M. (1986b) Intermediary Organization of the Skeleton Vol. II. CRC Press, Boca Raton.

Fyhrie, D. P. and Carter, D. R. (1986) A unifying principle relating stress to trabecular bone morphology. $J$. orthop. Res. 4, 304-317.

Fyhrie, D. P. and Carter, D. R. (1990) Femoral head apparent density distribution predicted from bone stresses. J. Biomechanics 23, 1-10.

Fyhrie, D. P. and Hollister, S. J. (1990a) A tissue strain remodeling theory for trabecular bone using homogenization theory. Trans. 36th $O R S$, p. 76.

Fyhrie, D. P. and Hollister, S. J. (1990b) Comparison of a trabecular tissue strain remodeling theory to experimental results. Trans 36th ORS, p. 107.

Galante, J. O. (1988) Clinical results with the HGP cementless total hip prosthesis. In Non-Cemented Total Hip Arthroplasty (Edited by Fitzgerald, R. H.), pp. 427-432. Raven Press, New York.

Galante, J. O., Sumner, D. R., Turner, T. and Barden, R. (1986) Fixation in total knee arthroplasty: fiber metal. In Total Arthroplasty of the Knee: Proceedings of the Knee Society $1985-1986$ (Edited by Rand, J. A. and Dorr, L.), pp. 236-248. Aspen Publishers, Rockville.

Galante, J. O. and Jacobs, J. (1992) Clinical performances of ingrowth surfaces. Clin. Orthop. Rel. Res. 276, 41-49.

Goldstein, S. A., Matthews, L. S., Kuhn, J. L. and Hollister, S. J. (1991a) Trabecular bone remodeling: an experimental model, J. Biomechanics 24, (Suppl.) 135-152. 
Goldstein, S. A., Matthews, L. S., Choi, K., Jepsen, K. J. and Shulick, A. M. (1991b) The effect of prosthesis surface geometry on implant stability and tissue ingrowth. Trans. 37 th ORS, p. 92.

Hainau, B., Reimann, I., Dorph, S., Rechnagel, K., Henschel. A. and Kragh, F. (1989) Porous-coated knee arthroplasty: a case report concerning bone ingrowth. Clin Orthop. Rel. Res. 239, 178-184.

Hedley, A. K., Clarke, I. C., Kozinn, S. C., Coster, I., Gruen, T. and Amstutz, H. C. (1982) Porous ingrowth fixation of the femoral component in a canine surface replacement of the hip. Clin. Orthop. Rel. Res. 163, 300-311.

Hollister, S. J., Fyhrie, D. P., Jepsen, K. J. and Goldstein, S. A. (1991a) Application of homogenization theory to the study of trabecular bone mechanics. J. Biomechanics 24, 825-839.

Hollister, S. J., Kikuchi, N. and Goldstein, S. A. (1991b) Effects of implant interface design on bone ingrowth predicted using topology optimization. Trans. 37th ORS, p. 108.

Huiskes, R., Weinans, H., Grootenboer, H. J., Dalstra, M., Fudala, B. and Slooff, T. J. (1987) Adaptive bone-remodeling applied to prosthetic-design analysis. $J$. Biomechanics 20, 1135-1150.

Hungerford. D. S. and Kenna, R. V. (1983) Preliminary experience with a porous-coated total knee replacement used without cement. Clin. Orthop. Rel. Res. 176, 95-107.

Hungerford, D. S., Krackow, K. A. and Lennox, D. W. (1988) The PCA primary and revision hip systems. In NonCemented Total Hip Arthroplasty (Edited by Fitzgerald, R. H.), pp. 433-450. Raven Press, New York.

Jasty, M. and Harris, W. H. (1988) Observations on factors controlling bone ingrowth into weight-bearing, porous, canine total hip replacements. In Non-Cemented Total Hip Arthroplasty (Edited by Fitzgerald, R. H.), pp. 175-190. Raven Press, New York.

Jee. W. S. S. (1983) The Skeletal tissues. In Histology: Cell and Tissue Biology (Edited by Weiss, L.), Sth edn, pp. 206-254. Elsevier, Amsterdam.

Kikuchi, N. (1986) Finite Element Methods in Mechanics.
Cambridge University Press, Cambridge.

Ko, C. C., Kohn, D. H. and Hollister, S. J. (1992) Stress analysis of the bone/implant interfacial zone accounting for localized architecture. Trans 38th ORS, p. 74.

Kohn, R. V. (1990) Numerical structural optimization via a relaxed formulation. Lecture given at NATO-ASI on Free Boundary Problems and Domain Optimization. University of Montreal, 1990.

Orr, T. E., Beaupre, G. S., Carter, D. R. and Schurman, D. J. (1990) Computer predictions of bone remodeling around porous-coated implants. $J$. Arthroplasty 5, 191-200.

Pederson. D. R., Brown, T. D. and Brand, R. A. (1991) Interstitial bone stress distributions accompanying ingrowth of a screen-like prosthesis anchorage layer. J. Biomechanics 24, 1131-1142

Sevitt, S. (1981) Bone Repair and Fracture Healing in Man. Churchill Livingstone, New York.

Spector, M. (1988) Current concepts of bony ingrowth and remodeling. In Non-Cemented Total Hip Arthroplasty (Edited by Fitzgerald, R. H.), pp. 69-86. Raven Press, New York.

Sumner, D. R.. Jacobs. J. J., Turner, T. M.. Urban, R. M. and Galante, J. O. (1989) The amount and distribution of bone ingrowth in tibial components retrieved from human patients. Trans. 35th ORS, p. 375.

Suzuki, K. and Kikuchi, N. (1990) Shape and topology optimization by a homogenization method. In Sensitivity Analysis and Optimization with Numerical Methods, ASME AMD-Vol. 115 (Edited by Saigal, S. and Mukherjee, S.). pp. 15-30. American Society of Mechanical Engineers, New York.

Taylor, J. E. (1986) Distributed parameter optimal structural design: some basic problem formulations and their application. In Advanced Study Institute on Computer Aided Design: Siructural and Mechanical Systems. Troia, Portugal.

Turner. T. M.,Urban, R. M. Sumner, D. R., Skipor, A. K. and Galante, J. O (1989) Bone ingrowth into the tibial component of a canine total condylar knee replacement prosthesis. J. orthop. Res. 7, 893-901. 